\title{
A FORMAÇÃO DE PROFESSORES EM UM CONTEXTO EMERGENTE ${ }^{1}$
}

\author{
TEACHER TRAINING IN AN EMERGING CONTEXT
}

\section{Gabriele Bonotto Silva ${ }^{2}$ \\ Clodoaldo Fernandes de Freitas ${ }^{3}$ \\ Vera Lucia Felicetti ${ }^{4}$}

RESUMO: A Educação Superior está em constante mudança devido a globalização, aos novos sujeitos que ingressam nos cursos de graduação e aos novos contextos emergentes. Pensando nisso, o artigo busca responder ao seguinte problema de pesquisa: Quais são os intervenientes na escolha e no percurso durante curso de Pedagogia por estudantes de uma instituição privada da grande Porto Alegre? Como referencial teórico utilizou-se os conceitos de educação emergente de Velasco e colaboradores (2017), assim como Dias Sobrinho (2014). A pesquisa apresenta abordagem qualitativa e analisa o corpus formado pelas respostas, de um grupo de estudantes do curso de Pedagogia, a um questionário enviado via Google Forms. Os dados foram analisados à luz da técnica de análise textual discursiva, baseada em Moraes e Galiazzi (2016), da qual emergiu a categoria escolha da profissão e o apoio formativo, as quais apontam para aspectos relacionados à vida escolar pregressa dos docentes, ao afeto pela profissão e envolvimento familiar no percurso da formação acadêmica.

Palavras-chave: Educação Superior. Escolha da Profissão. Pedagogia.

ABSTRACT: Higher Education is constantly changing due to globalization, to new incoming undergraduate students and to new emerging contexts. With this in mind, the present article aims to address the following research question: What are the key factors in students choosing and completing the Education program at a private institution in the Porto Alegre metropolitan area?

\footnotetext{
1 O presente trabalho foi realizado com apoio da Coordenação de Aperfeiçoamento de Pessoal de Nível Superior Brasil (CAPES) - Código de Financiamento 001

2 Doutoranda em Educação pela Universidade La Salle (Canoas/RS/Brasil). Bolsista CAPES/PROSUC. Professora do curso de Pedagogia na Cesuca - Faculdade Inedi. Especialista em Educação Básica. E-mail: gabybonotto@gmail.com

${ }_{3}^{3}$ Professor do Colégio Militar de Manaus e Mestrando em Educação no Mestrado Interinstitucional do Programa de Pós-graduação em Educação da Universidade La Salle de Canoas e da Faculdade La Salle de Manaus.

4 Doutora em Educação Professora do Programa de Pós-graduação em Educação da Universidade La Salle. Coordenadora do Grupo de Estudos Relacionados aos Estudantes (GERES) E—mail: vera.felicetti@,unilasalle.edu.br e verafelicetti@gmail.com
} 
We assumed theoretical concepts from emerging education by Velasco and collaborators (2017), as well as Dias Sobrinho (2014). This research uses a qualitative approach and analyzes a corpus compiled from the answers to a questionnaire sent via Google Forms, completed by a group of students in the Education program. The data were analyzed according to textual discourse analysis, based on Moraes and Galiazzi (2016), leading to the categories choice of profession and training support, which indicate aspects related to the prior academic life of teachers, their fondness for the profession and family involvement in their academic development.

Keywords: Higher Education. Choice of Profession. Education.

\section{INTRODUÇÃO}

A escolha da profissão é um passo importante na vida das pessoas, com atenção neste artigo a escolha na caminhada acadêmica. Ao optar por um curso de Graduação, os estudantes ingressam em um novo percurso de vida, de anseios e modos de estar e de fazer enquanto estudante. Contexto este repleto de mudanças e desafios, visto que a dinâmica na Educação Superior é diferente da vivida no Ensino Médio, no qual os estudantes são acompanhados de uma maneira mais próxima ou melhor dizendo, há uma cobrança mais direcionada, por parte do professor, ao que o discente necessita realizar. Já no contexto acadêmico, do estudante se espera uma independência e autonomia maior quanto às atividades e dinâmicas atinentes a este grau de ensino. Assim, esperase do estudante iniciativas e comprometimento capaz de o envolver no curso e no todo que a instituição de Educação Superior pode a ele oferecer, desenvolvendo, então, o sentido de pertencimento ao novo contexto, fortalecendo e consolidando seu percurso acadêmico de modo que ele possa superar as dificuldades encontradas até a integralização do curso.

Entre as diferentes opções de escolha a uma carreira na graduação, a licenciatura em Pedagogia é um dos cursos escolhido por aqueles que almejam trabalhar como professores na Educação Infantil e nos Anos Iniciais do Ensino Fundamental. Ao pensar sobre a escolha e o percurso desses estudantes, futuros professores, surgiu a pesquisa em questão, que foi realizada com 29 estudantes de licenciatura em Pedagogia de uma faculdade da região metropolitana de Porto Alegre/RS.

Para responder ao problema de pesquisa: Quais são os intervenientes na escolha e no percurso durante curso de Pedagogia por estudantes de uma instituição privada da grande Porto Alegre?, o artigo foi dividido em partes. O referencial teórico, denominado Educação Superior em Contextos Emergentes, utilizou os conceitos de educação emergente de Velasco e colaboradores (2017), e de Dias Sobrinho (2014), além de dados do Censo da Educação Superior de 2016 (INEP, 
2016). A metodologia que indica a forma da coleta de dados através do Google Forms e a análise feita a partir de Moraes e Galiazzi (2016). Os resultados e discussões que apresentam a categoria que emergiu durante a análise: Escolha da Profissão e o percurso formativo. Por fim, as considerações finais que retomam os resultados e propõem novas pesquisas sobre a temática.

\section{EDUCAÇÃO SUPERIOR EM CONTEXTOS EMERGENTES}

O campo da Educação Superior brasileira está em constante transformação. Inserida em uma complexa teia que envolvem acesso do seu egresso ao mercado de trabalho, qualificação profissional, desenvolvimento da cidadania, entre outros, os estudantes enfrentam diversos obstáculos em seu percurso acadêmico.

No percurso do estudante no contexto da Educação Superior, verifica-se uma trama de sentimentos, expectativas, alcances e fracassos (DORIO; CORTI, 2014). Em razão desta modalidade estar em transformações causadas por influências políticas, governamentais e empresariais, assim ensejam mudanças nos currículos, cursos, formas de ensinar e aprender, etc. Essas variáveis, somadas ao número de estudantes ingressantes e suas histórias, constituem em problema emergente no universo da pesquisa sobre a Educação Superior. Assim, "As interfaces constitutivas dos percursos formativos de professores são vastas, bem como, suas possibilidades nas mais variadas facetas do conhecimento científico e humano.” (COSTA, 2019, p.84)

Os contextos emergentes também têm como intuito promover o reconhecimento da sua própria legitimidade, assim como o reconhecimento da legitimidade do outro e para isso os participantes desses contextos necessitam desenvolver:

[...] capacidades e talentos que lhe permitam viver e sobreviver na profissão escolhida, ao mesmo tempo, mudar de área ou de profissão no decurso de sua própria vida, já que inúmeras profissões estão surgindo em função do acelerado desenvolvimento científico e tecnológico. Muitas delas estão emergindo em áreas fronteiriças, em áreas inter e transdisciplinares.

Ter acesso e dominar as diferentes fontes de informações e, ao mesmo tempo, desenvolver sua capacidade crítica no sentido de melhor reconhecer a confiabilidade de suas fontes e poder avaliá-las com maior capacidade de discernimento.

Aprender a viver/conviver com mais sabedoria, compreensão, respeito e generosidade (MORAES, 2003, p. 159).

Essa fronteira virtual apresentada pelo autor supracitado, que fala sobre a inter e transdisciplinaridade, também aparece na concepção de contexto emergente de Velasco (2017), quando afirma que: 
É nessa nova maneira de olhar o currículo: complexo ou transcomplexo onde seus componentes curriculares passaram por uma metamorfose transcendental. De um lado os conteúdos: transdisciplinar, contextual, emergente, irrestrito e não-finito, o oposto do design tradicional curricular disciplinado, definido, limitado em tempos e espaço e que permitiu treinar profissionais como algo definido, em "pacote acadêmico" e que na realidade está faltando de outras qualidades (p. 14).

Essa complexidade apresentada e refletida por Velasco (2017), e que pode também ser inferida nos apontamentos de Moraes (2003), apresenta problemas que afligem a sociedade global e aponta que novas atitudes e paradigmas educacionais são fundamentais para uma reorganização social. Por meio de um processo denominado de nova gênese na Educação, Velasco (2017) afirma que paradigmas educacionais emergentes, como a Educação Complexa e Transdisciplinar podem promover uma revolução educacional. Para este autor, é emergente o aprofundamento nas tentativas de encontrar maior praticidade didática e curricular, baseando-se na teoria educacional transcomplexa, a qual pretende recivilizar o ser humano, no meio complexo e incerto.

Pode-se trazer à discussão a contribuição de Thomas (2007), que discorre a respeito do choque escolar acadêmico. Este pode ser compreendido como a sensação que os estudantes têm ao se sentirem despreparados frente à realidade da Educação Superior, fato que merece importante análise ao se investigar a realidade discente e sua transição. A responsabilidade adquirida, o gerenciamento de carga horária e, por vezes, a ausência de um feedback que permitam aos estudantes aprimorarem e revisarem suas rotinas, corroboram com esse fenômeno.

Tendo em vista a emergência das soluções de tais questões, Thomas (2007) expõe duas abordagens possíveis de aprendizado: aquelas centradas no professor, onde os estudantes são referenciados como "vasos vazios" que serão gradativamente preenchidos pelos conhecimentos daquele que o detém, o professor, e as centradas no estudante, onde apresenta-se a ideia de que cada estudante possui sua forma de compreender e trazer consigo experiências e conhecimentos particulares, considerando-os construtores de seu próprio significado.

Velasco (2017) sugere que os contextos emergentes surgem com uma finalidade transformadora para a educação. Essa transformação pode se dar tanto no âmbito da pesquisa quanto na prática educacional. Nesse sentido, ela segue além, pois promove uma intervenção na racionalidade na pedagogia e na educação, auxiliando a dirigir os processos de formação e a buscar o reconhecimento das subjetividades.

Para a realização dessa transformação, exige-se aos atores desse processo de formação maior vigor em suas dinâmicas de trabalho. Esse vigor diz respeito, então, a atender contextos formativos e sociais (família, sociedade, comunidade, cidade, região e país) na intenção de satisfazer esses contextos e integrar as necessidades particulares e coletivas (VELASCO, 2017). 
No âmbito do currículo, Molina e Correa (2017) apontam a necessidade de reorganização curricular, validando a avaliação da qualidade da educação por meio de indicadores de transformação na sociedade. Dentre esses indicadores, são apontadas a inclusão social, o senso de pertencimento em um espaço, entre outros, os quais são indicadores ligados diretamente aos estudantes.

Além do currículo, outro importante olhar deve ser dedicado ao estudante. Moraes (2003) afirma que as metodologias no contexto emergente devem levar em conta a presença de um sujeito autoprodutor e autodeterminado em sua estrutura organizacional, a tomada de consciência de seus processos auto organizacionais, além do reconhecimento da necessidade de uma formação contextualizada. Nesta perspectiva, a educação deverá percorrer caminhos onde possa valorizar, não um ensino homogêneo e massificado, mas sim orientado nas subjetividades e diferenças, ultrapassando obstáculos existentes na relação entre formação e sociedade, seja por meio de recursos tecnológicos, estruturais e humanos.

Outro ator essencial no contexto da Educação Superior é o professor. Nesse aspecto, Garcia (2017) aponta a necessidade de uma formação de professores a partir de uma perspectiva complexa e expõe como emergente a aplicação da interdisciplinaridade, tornando a educação mais orgânica. Através de novas rotas que guiem fluidamente a educação no século XXI, busca conceitos teóricos e epistemológicos baseados na complexidade, de forma que o ensino avance por meio do pluralismo ideológico, da tolerância, da crítica capaz de repensar realidades, de provocar uma autorreflexão e transformação da educação.

Diante das questões que perpassam o contexto emergente da Educação Superior, no qual a complexidade se entremeia no currículo, no reconhecimento das diferenças entre os estudantes e na reflexão, verifica-se uma fonte bastante rica para a condução de uma pesquisa com estudantes de Educação Superior, cujo objetivo é conhecer como ocorre a escolha pelo curso e o percurso desse grupo de estudantes em uma instituição de Educação Superior privada.

\section{METODOLOGIA}

A pesquisa foi realizada através de um formulário do Google forms enviado para 29 estudantes do curso de Pedagogia de uma faculdade privada na região metropolitana de Porto Alegre/RS no computo de uma das atividades com eles realizadas em uma disciplina do curso. Os questionamentos expressos no formulário solicitavam dados sobre o sexo, a idade e o semestre que os estudantes estão cursando. Além disso, o formulário contava com perguntas abertas, a saber: Por que você escolheu este curso de graduação?; Como sua família apoia (ou não apoia) você a 
fazer esta faculdade? Os estudantes não necessitaram se identificar. As respostas, permitiram à docente melhor conhecer seus estudantes e, também, proporcionou problematizar com eles aspectos relacionados à formação inicial no curso e as inquietudes que perpassam o processo formativo. Além disso, no escopo do corpus formado pelas respostas, emergiram diferentes categorias, das quais se elegeu uma a ser aqui apresentada, devido ao escopo deste artigo: Escolha da profissão e o apoio formativo.

Responderam ao questionário 29 estudantes, sendo 96,55\% do sexo feminino e 3,45\% do sexo masculino. 41,38\% dos respondentes tinham entre 21 e 25 anos, 17,24\% mais de 25 e até 30 anos, 17,24\% mais de 30 até 35 anos e 24,14\% afirmaram que possuem mais de 35 anos, demonstrando um grupo de idades heterogêneas. Quanto a cor ou raça, 79,31\% declararam cor branca, $10,34 \%$ parda e 10,34\% preta. Os respondentes são identificados na pesquisa como R e o número correspondente a ordem de preenchimento do formulário, ou seja, de R1 até R29.

A análise do corpus formado pelos dados coletados, através do questionário, foi feita segundo orientações de Moraes e Galiazzi (2016). Na visão desses autores, a análise textual discursiva busca um processo de construção da compreensão no qual surgem novos entendimentos. Esse processo é cíclico e seus elementos principais são: a unitarização, a categorização, resultando no metatexto.

$\mathrm{Na}$ unitarização ocorreu a desmontagem dos documentos. Na categorização, o objetivo foi criar categorias, estabelecendo relações entre os elementos unitários, formando grupos que revelam elementos próximos. O metatexto foi construído a partir da categoria que emergiu após a leitura e da análise do corpus da pesquisa.

\section{ESCOLHA DA PROFISSÃO E O PERCURSO NO CURSO DE PEDAGOGIA}

Os 29 respondentes, matriculados no curso de Pedagogia, dissertaram sobre a pergunta "Por que você escolheu esse curso de graduação?" dos quais 17 memoraram que sempre pretenderam atuar na área da educação, ou ainda que a escolha foi feita a partir de memórias da sua vida escolar e de se identificar com a profissão. Neste sentido, Tardif (2014) diz que as experiências vividas pela pessoa no âmbito da família e da trajetória escolar influenciam fortemente à escolha da profissão, ou seja, ao longo desse período são adquiridos saberes oriundos dessa socialização que se tornam elementos marcantes relacionados à sua memória afetiva. Isto fica claro através da fala da respondente R6 que afirma que sua escolha se deu "Por acreditar que serei uma professora melhor do que as que tive". Nesta fala, percebe-se que a escolha da profissão está ancorada em referenciais da sua socialização escolar, que se evidencia em lembranças relacionadas ao 
proceder de suas professoras. R7, por sua vez, escreve que sempre amou a educação e "desde pequena sempre quis ser professora".

Nesta direção, a escolha do curso de Pedagogia tem destaque nos estudos de Nogueira e Pereira (2010, p.20) que encontram em entrevistas com estudantes de Pedagogia com perfil social e escolar mais elevado do que o normalmente apresentado nas pesquisas que: "[ ] o gosto pela área de educação também é forte e foi reconhecido desde sempre”. Isto põe em evidência que a escolha pelo curso tem íntima relação com o querer

$\mathrm{Na}$ fala da respondente $\mathrm{R} 7$, parece haver vestígios positivos de sua experiência de infância, pois, a sua convicção pela profissão é evidenciada nos componentes afetivos de sua fala referentes a profissão e é traduzida por uma evidente identificação com a profissão. Assim sendo, a “[...] a identidade não é um dado adquirido, não é uma propriedade, não é um produto. A identidade é um lugar de lutas e de conflitos, é um espaço de construção de maneiras de ser e se estar na profissão” (NÓVOA, 2007, p. 16).

R12 afirma: "A minha escolba já vinha do Ensino Médio, quando o concluir, sempre disse que faria a Pedagogia". Nesta fala, se evidencia uma construção do processo de escolha que se concretiza no Ensino Médio. Para Tardif (2014) o eu profissional se constrói nessa temporalidade onde a pessoa vivencia diversas interações sociais que são contribuintes importantes para esta escolha. Neste sentido, um estudo realizado pelo Instituto Península em 2019, que retrata 2,2 milhões de professores que atuam no Brasil, mostra que dois em cada três professores escolheram a docência como primeira opção de carreira. Fica evidente no estudo que "Há 3 razões para a escolha da profissão: Dom e vocação (43\%), Fazer a diferença na vida dos alunos (23\%) e Gostar de trabalhar com crianças e jovens (15\%).” (INSTITUTO PENINSULA, 2019, p.18)

A respondente R24 atribui a sua escolha relacionada a um sonho de profissão, visto que: "Pois sempre sonhei em exercer essa linda profissão". Nesta fala, constata-se que a escolha da profissão foi um projeto de vida, e que a sua realização proporcionou uma notória satisfação. A escolha da profissão docente, apresenta evidências do que já foi construído durante o período experienciado enquanto estudante, e tem forte relação com a formação inicial, ou seja, conceitos e crenças que os estudantes do curso se apropriam e passam a fazer parte de seu discurso.

Por outro lado, observa-se que algumas respondentes têm como cerne da escolha a aprendizagem do outro, a crença de que à educação é necessário haver afetividade e encantamento para que ocorra uma melhor aprendizagem. R9 deixa evidente isso em seu testemunho: "por acreditar em uma educação mais eficaz quando envolvida na afetividade". Para Tardif "[...] as relações dos professores com os saberes nunca são relações estritamente cognitivas: são relações mediadas pelo trabalho que lhes fornece princípios para enfrentar e solucionar situações cotidianas”. (2014, p. 17). Neste 
sentido, o professor que percebe cada estudante como único e que cada um é diferente e que aprende de forma igualmente diferente, no seu tempo, de acordo com suas potencialidades, está atendendo a heterogeneidade da turma e agindo com atenção ao processo de ensino e porquê não dizer com encantamento, como expressa R22: "encantamento pelo desenvolvimento da criança e por seu processo de aprendizagem".

Ao encontro do que R9 e R22 escreveram, estão as respondentes R16, R17 e R27 que pretendem ver mudanças em seus estudantes a partir de sua prática pedagógica. Os conceitos de afetividade, processo de aprendizagem, encantamento e transformação da realidade estão presentes nas falas desses respondentes, que parecem terem desenvolvido o sentido de pertencimento no curso. Para Pitta (2018), o amor pela profissão, o encantamento pela carreira; são aspectos que permeiam o fazer e o ser no dia a dia da sala de aula de professoras dos anos iniciais, egressas de curso de Pedagogia ou Magistério. Para a autora tais aspectos são fundamentais na profissão docente. Assim, "A possiblidade de construir uma sociedade melhor é apontada por 74\%" dos professores" participantes da pesquisa realizada pelo Instituto Peninsula (2019, p.19) quando questionados sobre aspectos mais positivos da profissão.

Os respondentes também demonstraram seus objetivos após a conclusão do curso de Pedagogia, indicando, inclusive, a intensão de formação continuada. R15 afirma que escolheu a profissão de pedagogo e seguir em uma especialização "por que era um sonho trabalhar com Pedagogia na área hospitalar" e R4 "Porque quero trabalhar como psicopedagoga" o que evidencia a necessidade de seguir com a formação. Nesta direção, Carvalho (2005), aponta que os professores têm grande importância no processo de formação continuada, na medida em que colaboram com sua própria prática, "ganhando o professor vez e voz, exercendo o papel de ator coletivo na transformação do cotidiano escolar e para além dele.” (CARVALHO, 2005, p. 97).

A escolha da profissão pode estar entrelaçada ao vivido e ao não vivido enquanto estudante, o que dá um caráter próprio de escolha a cada pessoa. Para Nogueira e Pereira (2010, p.18),

É interessante compreender como os elementos que finalmente levam à decisão por um curso vão sendo construídos ao longo da trajetória de vida dos sujeitos, em função dos múltiplos laços sociais que eles vão estabelecendo (ou rompendo) e das experiências que vão tendo na família, na escola e em sua rede social mais ampla.

Para as autoras, as escolhas que os sujeitos fazem na área educacional não podem ser atribuídas a sua posição social de origem, sem considerar gostos, preferências e objetivos. Logo não podem ser mecanicamente deduzidos de sua posição social de origem. 
Ao escolher a profissão os estudantes estão assumindo uma nova postura, um novo caminho que será traçado pelo paradigma emergente e que o colocará no centro de um processo de uma Educação Complexa e Transdisciplinar (VELASCO, 2017). A escolha, pode não ser feita com a consciência de que poderá fazer parte de uma revolução educacional, porém os próximos questionamentos respondidos por eles, demonstrarão como estão imbuídos nessa revolução durante o percurso do curso de graduação, deixando implícito o deslumbrar para a possiblidade de construir uma sociedade melhor

Assim como a escolha da profissão demonstrou aspectos importantes nas respostas, o apoio familiar aos estudos também obteve destaque, pois, parte recebe este suporte no seu ciclo familiar, seja de forma financeira ou apenas quanto à estímulos para a continuidade de seus estudos. Dentre os que afirmam receber apoio familiar, destacam-se os respondentes R2 “A minha família apoia e entende que não tenho tanto tempo para conversar e ficar com eles", R27 "Bah, eles apoiam muito cuidam de meus filhos pra eu ir na aula e me impulsionam se desanimo" e R17 "Me incentivam sempre e me ajudam, se caso falte algo.” As falas dos respondentes R2, R27 e R17 evidenciam como algumas famílias demonstram o seu apoio para que os estudantes deem continuidade ao seu curso superior, seja ajudando financeiramente, cuidando dos filhos ou então não deixando que desanimem.

Pôde-se perceber que, apesar de alguns relatarem sobre a existência de um apoio familiar para a permanência na Educação Superior, eles revelam ao mesmo tempo uma outra face por detrás deste mesmo apoio: a não concordância de membros da família quanto a sua permanência no curso de Pedagogia e não na Educação Superior propriamente dita, sendo isto justificado pelo retorno financeiro que o curso possa dar, o qual não tem expectativas pela família. Assim como evidencia R18: "A família acha importante, mas não dá relevância. Não entendem quando é preciso abdicar de algumas coisas como um passeio ou uma visita, para os estudos, acham que poderia faltar, deixar de fazer etc".

Quanto às respostas de teor negativo, os entrevistados limitaram-se a explanar mais profundamente os motivos pelos quais os familiares acabavam não demonstrando o seu apoio total. Dos poucos que mencionaram, novamente, há o fato da não concordância na permanência no curso, passando por uma incompreensão dada pelos que não presenciam o dia-a-dia destes estudantes, ou pelo próprio, já mencionado, retorno financeiro desejado. R19 explana sobre o assunto: "Apoia por não terem tido a oportunidade de continuar os estudos, mas acham que não deveria ter escolbido essa profissão, porque não vou ter retorno financeiro". Assim como R6: "Meu marido não concorda com esta segunda graduação. Meus pais se orgulham e desejam que eu tenha sucesso na carreira" e R1: "A maioria não entende e acha que não preciso".

Nesta direção, os aspectos mais negativos apontados na pesquisa do Instituto Peninsula (2019), acerca da profissão, estão relacionados a dois fatores, a baixa remuneração e a 
desvalorização social do professor. Esta desvalorização dos professores também é apontada por autores como Carvalho (2005), Tardif (2012) e Nóvoa (2007) cujos trabalhos apontam a desvalorização dos professores sendo influenciada pela não autonomia docente o que não lhe dá a possibilidade de ocupar o seu lugar no contexto educacional.

Ainda, os estudantes revelam situações em que o apoio familiar não existia, mas com o tempo, passaram a ter. R7: "No início foi difícil, pois sai de outro curso porque men pai queria muito que en fosse contadora. Fiz o vestibular escondida, passei, tive dificuldade no início para pagar pois pagava sozinha logo comecei a trabalhar na área e desde então nunca mais saí. Hoje meus pais ficam muito felizes porque faço o que en gosto". Neste excerto, percebe-se a relutância inicial da família pela escolha do curso Pedagogia, mas através da realização pessoal da estudante, ficou evidente para os pais a necessidade de mudar a postura em relação ao curso de graduação escolhido.

Destaca-se a diversidade de respostas em relação ao apoio familiar. Nesse sentido, além da escolha da profissão o percurso passa a ser objeto de estudo, por apresentar nuances e facetas diferenciadas, levando em consideração as especificidades de cada estudante e seus contextos. Moraes (2003) afirma que o foco principal precisa ser no aluno, em sua formação contextualizada e na valorização do ensino heterogêneo que valoriza as diferenças e subjetividades. Cabe, então, a instituição de ensino e aos professores fazer essa análise inicial dos contextos e dos sujeitos pertencentes ao curso, para adaptar o currículo e as metodologias para melhor estabelecer um vínculo com os estudantes e colocá-los no centro do processo de aprendizagem. Nesta acepção, Gracía (2017) apresenta, como processo emergente na educação, o currículo crítico, uma forma de promover a compreensão racional dos problemas sociais a partir do trabalho da criticidade e reflexividade dos estudantes e dos professores.

Assim como o apoio familiar, ficou evidente, o apoio do professor também se mostrou relevante. A motivação exercida pelos professores e a admiração que estes estudantes têm por eles são estímulos para seguirem no curso, o que aparece na resposta de R24: "Gosto muito de estudar aqui pois aqui tem professores maravilhosos, são excelentes profissionais e gosto muito também da instituição" e R26: "Minha força de vontade e os Professores que são maravilhosos" e na de R15: "motivação dos professores". Tais depoimentos evidenciam a importância dos professores na manutenção dos estudantes de graduação, evitando ou diminuindo a desistência por parte deles. Essa evidência corrobora com Tardif (2012), quando afirma que o professor necessita articular saberes para o agir pedagógico.

Nesse mesmo sentido, Garcia (2017) destaca a necessidade de os professores atuarem através de uma perspectiva emergente, de forma transdisciplinar e buscando uma educação orgânica. Conforme os relatos dos estudantes, os professores da instituição parecem seguir princípios em que os conceitos estão baseados no pluralismo ideológico, na autorreflexão e 
transformação da educação, demonstrando a sua motivação pela docência e por alcançar as diferentes realidades apontadas pelos respondentes.

\section{CONSIDERAÇÕES FINAIS}

Muitas das respostas, presentes neste estudo sobre a escolha da profissão, estão pautadas na vida escolar pregressa dos estudantes. Seja pelo encantamento gerado pela profissão docente ou pelos desencantamentos. Os estudantes revelam que a escolha teve viés emocional, destacando as memórias do seu percurso escolar e as possibilidades vistas, a partir dessas memórias, para a profissão. E embora em várias respostas há evidencias da não aceitação pela escolha do curso Pedagogia, devido à valorização da profissão, seja ela social ou em termos de retorno financeiro, é latente nesses estudantes o querer ser professor, e muitas vezes implícito, é evidente a essência enquanto pessoa de querer fazer diferente em sociedade, em ser diferente, em contribuir para com um mundo melhor. É latente a ansiedade de promover uma transformação social.

Nesta acepção, coaduna-se com Velasco (2017) quando o autor considera como temática emergente o aprendizado do enfrentamento ao contrário, a multiplicidade de cenários aos quais somos postos, onde muitas vezes não é valorizada a essência da educação, a essência humana, o sentido do ser mais do que o ter mais. É esquecer a relação entre o ser e o ter, onde um completa o outro, sem esquecer que a realização pessoal remete a realização da pessoa, muitas vezes mais que realização financeira isolada do ser pessoa, do seu humano.

\section{REFERÊNCIAS}

CAPRA, F. A Teia da Vida. 6a edição. São Paulo: editora Cultrix. 2007.

CARVALHO, Janete Magalhães. O não-lugar dos professores nos entrelugares de formação continuada. Revista Brasileira de Educação. Rio de Janeiro, n. 28, p. 96-107, jan./abr. 2005.

COSTA, Douglas Pereira da. GINCANAS COMO ESPAÇO DE FORMAÇÃO DOCENTE: das (inter)faces possíveis em um curso de Pedagogia. Cadernos Cajuína, V. 4, N. 1, 2019, p. 84 - 104. Disponível em: https://cadernoscajuina.pro.br/revistas/index.php/cadcajuina/article/view/260

DORIO, Imma; CORTI, Franciele. El primer año em la universidad. In: GONZÁLEZ, Manuel Álvarez et al. Persistir com éxito en la universidad. Barcelona: LAERTE, 2014, p. 157-174.

GARCIA, Janeth Saker. Saberes Emergentes en el contexto de una nueva formación docente. In: VELASCO, Juan Miguel González et al. Educación Emergente: El Paradigma del Siglo XXI. Bolívia: PRISA, 2017, p. 32-39. 
GRACÍA, Denny Lloreda. Currículo crítico, una mirada inclusiva desde la complejidad. In: VELASCO, Juan Miguel González et al. Educación Emergente: El Paradigma del Siglo XXI. Bolívia: PRISA, 2017, p. 64-76.

INSTITUTO NACIONAL DE ESTUDOS E PESQUISAS EDUCACIONAIS ANÍSIO TEIXEIRA - INEP. Sinopse Estatística da Educação Superior 2016. Brasília: Inep, 2017. Disponível em: http://portal.inep.gov.br/basica-censo-escolar-sinopse-sinopse. Acesso em: 17 ago. 2018.

INSTITUTO PENINSULA. Retratos da carreira docente. Instituto Península Outubro 2019. Disponível em: https://www.institutopeninsula.org.br/para-65-dos-professores-formacao-einadequada-para-o-dia-a-dia-em-sala-de-aula/ Acesso em: 31 de ago. de 2020.

MOLINA, Cecilia Correa de; CORREA, Maribel Molina. Auto-organización curricular em el contexto de la emergência de la subjetividad del estudiante y la calidad de la educación. In: VELASCO, Juan Miguel González et al. Educación Emergente: El Paradigma del Siglo XXI. Bolívia: PRISA, 2017, p. 22-31.

MORAES, M. C. Educar na biologia do amor e da solidariedade. Rio de Janeiro: editora Vozes, 2003.

MORAES, Roque; GALIAZZI, Maria do Carmo. Análise textual discursiva. Ijuí: Editora Unijuí, 2016.

NÓVOA, Antônio. Vidas de Professores. Porto: Porto Editora, 2007.

PITTA, Priscilla de Souza. Razões que mobilizam o exercício docente nos anos iniciais da Educação Básica. 95 f. Dissertação (Mestrado em Educação). Universidade La Salle. Canoas, 2018. Disponível em: http://repositorio.unilasalle.edu.br/handle/11690/1130. Acesso em 05 de ago de 2020.

TARDIF, Maurice. Saberes docentes e formação profissional. Petrópolis, RJ: Vozes, 2012.

THOMAS, Liz. Improving Student Retention in Higher Education: the role of teaching and learning. New York: Routledge, 2007.

VELASCO, Juan Miguel González. Educación emergente: Bases y prospectiva para el siglo XXI. In: VELASCO, Juan Miguel González et al. Educación Emergente: El Paradigma del Siglo XXI. Bolívia: PRISA, 2017, p. 9-21. 